\title{
Mucopolysaccharidosis type 2, attenuated form
}

INSERM

\section{Source}

INSERM. (1999). Orphanet: an online rare disease and orphan drug data base.

Mucopolysaccharidosis type 2, attenuated form. ORPHA:217093

Mucopolysaccharidosis type 2, attenuated form (MPS2att), the less severe form of MPS2 (see this term), leads to a massive accumulation of glycosaminoglycans and a wide variety of symptoms including distinctive facies, short stature, cardiorespiratory and skeletal findings. It is differentiated from mucopolysaccharidosis type 2 , severe form (see this term) by the absence of cog nitive decline. 